\title{
Anomalous Reaction of 4-Chloro-7-nitrobenzofurazan with Thiol Compounds
}

\author{
By KATSUTOSHI NITTA, * STELLA C. BRATCHER and MARTIN J. KRONMAN \\ Upstate Medical Center, Department of Biochemistry, State University of New York, \\ Syracuse, NY 13210, U.S.A.
}

(Received 25 April 1978)

\begin{abstract}
The kinetics of reaction of 4-chloro-7-nitrobenzofurazan with thiol groups at $\mathrm{pH}$ values above 5 cannot be accounted for solely on the basis of formation of a single product, the 4-thio derivative. Spectroscopic observations indicate that, in addition to the 4-thio derivative, at least two other products are formed. One of these, referred to as $\mathbf{P}_{1}$, is most likely a reversible complex of thiol compound and 4-chloro-7-nitrobenzofurazan of the Meisenheimer type. The other product, $\mathrm{P}_{\mathbf{2}}$, which forms primarily when thiol compound is in a large excess, does not appear to result from direct reaction of thiol group and 4-chloro-7-nitrobenzofurazan, but may be a reaction of product $P_{1}$ and thiol compound. The coloured product, $\mathbf{P}_{\mathbf{2}}$, will react further with proteins, such as bovine serum albumin and Escherichia coli RNA polymerase. This reaction irreversibly destroys the catalytic activity of RNA polymerase. The implications of these observations for utilization of 4-chloro-7-nitrobenzofurazan as a protein-modifying agent are discussed.
\end{abstract}

$\mathrm{Nbf}-\mathrm{Cl}$ has proved to be a very useful reagent for introducing a fluorescent label into proteins. Reaction appears to occur primarily at thiol groups (Birkett et al., 1970a), although reports have appeared indicating reaction at amino (Birkett et al., 1970a) and tyrosyl (Ferguson et al., 1974) groups. One of the attractive features of this reagent is that the site of labelling can be readily determined from the spectroscopic properties of the product (Birkett et al., 1970a). Reactivity of thiol groups has been studied for papain, bromelein and ficin (Shipton et al., 1976), phosphorylases $a$ and $b$ (Dwek et al., 1972; Birkett et al., 1971), glyceraldehyde phosphate dehydrogenase (Birkett et al., 1970b), adenylate kinase (Price, 1972), and of tyrosyl groups for bovine heart mitochondrial adenosine triphosphatase (Ferguson et al., 1974), chloroplast coupling factor 1 (Cantley \& Hammes, 1976) and Escherichia coli $\left(\mathrm{Mg}^{2+} / \mathrm{Ca}^{2+}\right)-$ stimulated adenosine triphosphatase (Nelson et al., 1974). Since $\mathrm{Nbf}-\mathrm{Cl}$ is stable and will react over a wide range of $\mathrm{pH}$ values, the choice of $\mathrm{pH}$ for reaction seems to have been based in general on the intrinsic properties of the protein, such as its stability. Other than a preferential $\mathrm{pH}$-dependence for the $\mathrm{Nbf}-\mathrm{S}$ to Nbf-N transfer (Birkett et al., 1970a), there seems to

* Permanent address: Department of Polymer Science, Faculty of Science, Hokkaido University, Kita-ku, Sapporo 060, Japan.

Abbreviations used: $\mathrm{Nbf}-\mathrm{Cl}$, 4-chloro-7-nitrobenzofurazan (4-chloro-7-nitrobenzo-2-oxa-1,3-diazole); $\mathrm{Nbf-S}$, 4-nitro-7-thiobenzofurazan; Nbf-OHEtS, 4-(2'-hydroxyethylthio)-7-nitrobenzofurazan; Nbf-N, 4-amino-7-nitrobenzofurazan. be no hard and fast rule that relates $\mathrm{pH}$ and specificity of reaction. With the exception of the plant-derived proteolytic enzymes (Shipton et al., 1976), all of the proteins cited above were allowed to react with $\mathrm{Nbf}-\mathrm{Cl}$ in the $\mathrm{pH}$ range 7-8.

Considerations of stability led us to restrict studies of thiol reactivity in Escherichia coli RNA polymerase to $\mathrm{pH}$ values above 6 . We have shown that a single thiol group reacts very rapidly at $\mathrm{pH} 7.5$ with impairment of the elongation step of the transcription process catalysed by this enzyme (Bratcher \& Kronman, 1977). A parallel reaction of a relatively large but indeterminate number of thiol groups occurs at a much lower rate. To determine the basis for the unique reactivity of the single 'active-siterelated' thiol group, we studied the kinetics of reaction in some detail, including an examination of the $\mathrm{pH}$-dependence of the reaction rate (M. J. Kronman, K. Nitta \& S. C. Bratcher, unpublished work). Kinetic anomalies observed in these studies with RNA polymerase led us to examine comparable kinetic properties for the reaction of $\mathrm{Nbf}-\mathrm{Cl}$ with a simple thiol derivative, 2-mercaptoethanol. The anomalous kinetic behaviour observed with this simple system, together with spectroscopic observations that explain these results, are the subject of this report.

Subsequent to completion of our studies the report by Baines et al. (1977) came to our attention. Their investigations showed that a Meisenheimer-type complex (Meisenheimer, 1902) could be formed reversibly with $\mathrm{OH}^{-}$at alkaline $\mathrm{pH}$ at position $\mathrm{C}-6$ of $\mathrm{Nbf}-\mathrm{Cl}$. The anomalous kinetics that we report in 
the present paper support the view that a similar complex can be formed with thiol compounds. However, we also show that an additional product or products form that can react in an irreversible manner with proteins.

\section{Experimental}

$\mathrm{Nbf}-\mathrm{Cl}$ and 2-mercaptoethanol were obtained from Pierce, Rockford, IL, U.S.A., and Matheson-Coleman-Bell, Norwood, OH, U.S.A., respectively. The m.p. of the $\mathrm{Nbf}-\mathrm{Cl}$ was found to be $97^{\circ} \mathrm{C}$, corresponding to that reported previously (Ghosh \& Whitehouse, 1968). Dithiothreitol (grade A) and triethanolamine were products of Calbiochem, La Jolla, CA, U.S.A. All other chemicals were of reagent grade. With the exception of triethanolamine, which was recrystallized twice from hot water, all chemicals were used as received. Deionized charcoal-filtered water was used in preparing buffers. Nbf-OHEtS was prepared by a method similar to that of Allen \& Lowe (1973).

Absorption spectral measurements were made with a Cary $118 \mathrm{C}$ spectrophotometer with the most sensitive scales and zero suppression appropriate to the spectral changes encountered. Kinetic measurements were made at $15.0^{\circ} \mathrm{C}$ in thermostatically controlled cell holders. To initiate reaction of $\mathrm{Nbf}-\mathrm{Cl}$ with 2-mercaptoethanol or with RNA polymerase, a $1 \mathrm{ml}$ sample of the thiol species was equilibrated in the thermostatically controlled semi-micro cell, after which $0.02 \mathrm{ml}$ of concentrated $\mathrm{Nbf}-\mathrm{Cl}$ solution $(15-95 \mathrm{~mm})$ in $95 \%$ ethanol was added and the cell contents were mixed by inversion against a plasticfilm cell cover. Concentrations of Nbf-OHEtS formed in the reaction were calculated from the $A_{\mathbf{4 2 0}}$ by using a molar absorption coefficient of 13000 (Dwek et al., 1972).

\section{Results}

\section{Kinetics of reaction of $\mathrm{Nbf-Cl}$ with 2-mercaptoethanol}

The anomalous kinetic behaviour of RNA polymerase manifested itself in two kinds of observations: (a) plots of the apparent first-order rate constant against $\mathrm{Nbf}-\mathrm{Cl}$ concentration did not go through zero for either class of reactive thiol; $(b)$ the apparent second-order rate constants showed an unexpectedly small dependence on $\mathrm{pH}$ in the 7-8.5 range. Measurements could not be extended to much lower $\mathrm{pH}$ because of instability of the enzyme.

Similar kinds of measurements were therefore made for the reaction of $\mathrm{Nbf}-\mathrm{Cl}$ with 2-mercaptoethanol over the $\mathrm{pH}$ range 4-7.5. With the exception of a group of experiments carried out with an excess of 2-mercaptoethanol (see Fig. 2), all of the kinetic observations were made with a minimum molar ratio of $\mathrm{Nbf}-\mathrm{Cl}$ to 2-mercaptoethanol of 2:1. Observations were restricted to times corresponding to less than $4 \%$ consumption of $\mathrm{Nbf}-\mathrm{Cl}$. The kinetics were analysed as pseudo-first-order, but since such kinetics were anomalous (see below), we will refer to the rate constant, $k_{\text {app., }}$ as an apparent rate constant.

Plots of the apparent rate constant against $\mathrm{Nbf}-\mathrm{Cl}$ concentration at a constant 2-mercaptoethanol concentration are shown in Fig. 1. The concentrationdependencies at $\mathrm{pH} 7.00$ and 7.50 are highly anomalous; at pH7.50 the rate constant is nearly independent of $\mathrm{Nbf}-\mathrm{Cl}$ concentration over a 7 -fold range. At pH 7.00 a very weak dependence on concentration is observed, independent of the buffer employed. However, the best line through the experimental points by no means goes through zero. The rate constant at $\mathrm{pH} 6.00$ shows a much greater dependence on $\mathrm{Nbf}-\mathrm{Cl}$ concentration, but the curve likewise does not go through zero. The concentration-dependence of $k_{\text {app. }}$. at pH 5.00 appears to be normal for a pseudo-firstorder reaction. Similar observations were made below pH 5 (results not shown here). A more detailed kinetic analysis of the data is reserved for the Discussion section of this paper.

The kinetics of reaction where 2-mercaptoethanol was in excess were even more surprising (Fig. 2). Under conditions where we would expect a nearly 20 -fold increase in rate constant for the range of 2mercaptoethanol concentrations employed, a 6-fold decrease in rate constant is observed!

The above kinetic observations lead to the conclusion that the consumption of $\mathrm{Nbf}-\mathrm{Cl}$ and of 2 -

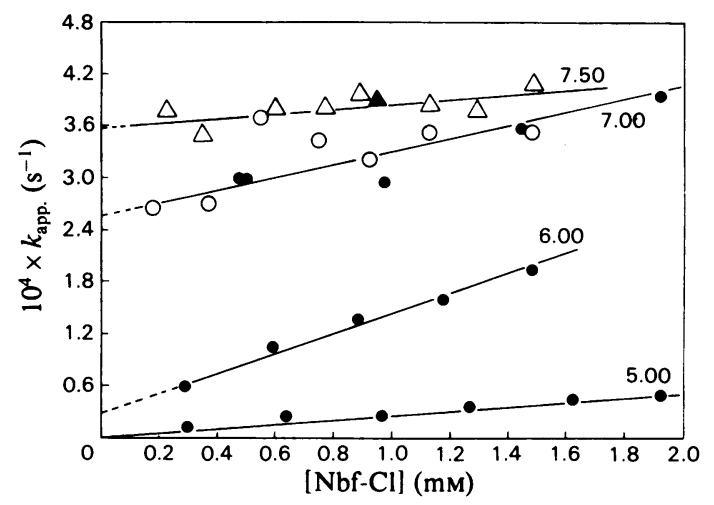

Fig. 1. Dependence of the apparent first-order rate constant on $\mathrm{Nbf-Cl}$ concentration for reaction of 2-mercaptoethanol with excess reagent at $15^{\circ} \mathrm{C}$

The numerical values of the $\mathrm{pH}$ of measurement are given in the Figure. The 2-mercaptoethanol concentrations were $0.034 \mathrm{~mm}$ at $\mathrm{pH} 7.00$ and $7.50,0.068 \mathrm{~mm}$ at $\mathrm{pH} 6.00$ and $0.137 \mathrm{~mm}$ at $\mathrm{pH} 5.00$. The buffer compositions were: $0.05 \mathrm{M}$-sodium citrate/citric acid at pH7.50 (४) and at 7.00, 6.00 and $5.00(\bullet), 0.05 \mathrm{M}-$ triethanolamine $\mathrm{HCl} / \mathrm{NaOH}$ at $\mathrm{pH} 7.50(\triangle)$ and $0.05 \mathrm{M}-\mathrm{KH}_{2} \mathrm{PO}_{4} / \mathrm{Na}_{2} \mathrm{HPO}_{4}$ at $\mathrm{pH} 7.00(\mathrm{O})$. 


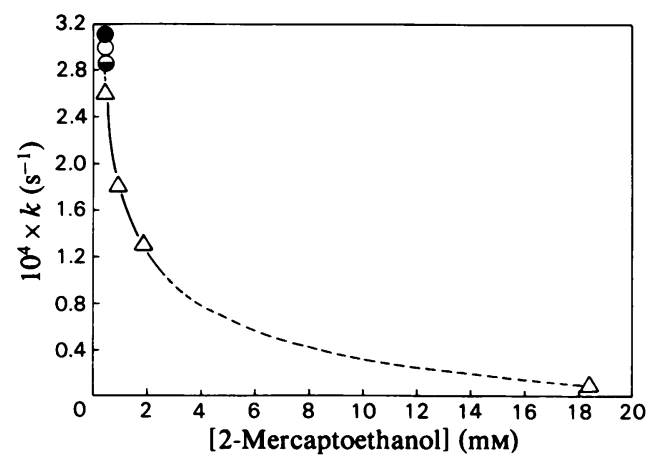

Fig. 2. Dependence of the apparent first-order rate constant on 2-mercaptoethanol concentration for reaction of $\mathrm{Nbf}-\mathrm{Cl}$ with excess 2-mercaptoethanol at $15^{\circ} \mathrm{C}$

The buffer was $0.05 \mathrm{M}$-triethanolamine $\mathrm{HCl} / \mathrm{NaOH}$ (pH 7.50). The $\mathrm{Nbf}-\mathrm{Cl}$ concentrations were $0.076 \mathrm{~mm}$ $(\triangle), 0.057 \mathrm{~mm}(\ominus), 0.039 \mathrm{~mm}(\odot)$ and $0.019 \mathrm{~mm}(\bullet)$.

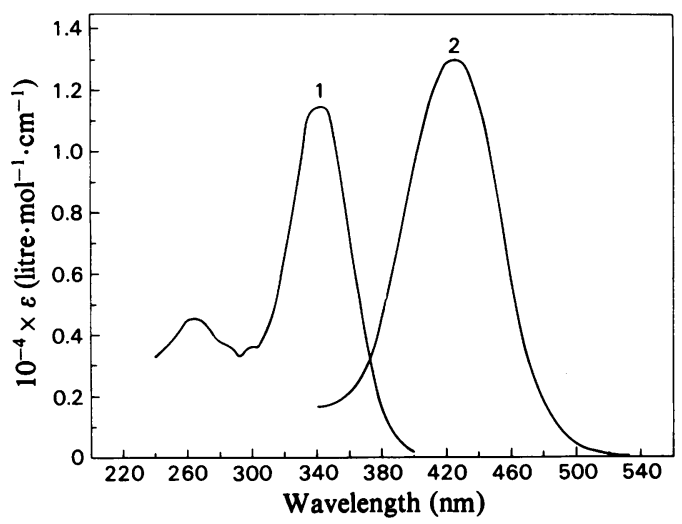

Fig. 3. Absorption spectra of $\mathrm{Nbf-Cl}$ (curve 1) and $\mathrm{Nbf}$ OHEtS (curve 2) in water adjusted to pH7.1

mercaptoethanol must give rise to products other than the Nbf-S derivative. For this reason we have examined the spectra of mixtures of $\mathrm{Nbf}-\mathrm{Cl}$ and 2mercaptoethanol during the course of the reaction, to detect products other than the Nbf-S derivative.

\section{Spectra of $\mathrm{Nbf-Cl/2-mercaptoethanol}$ and $\mathrm{Nbf-Cl}$ dithiothreitol reaction products}

To magnify spectral changes of reactant and products a difference spectral technique was employed by using tandem cylindrical cells $(2.00 \mathrm{~cm}$ path length per compartment) of the kind usually used for solvent perturbation measurements (Herskovits \& Laskowski, 1962). The usual arrangement of solutions was: reference beam ( $\mathrm{Nbf}-\mathrm{Cl}$, buffer); (2-mercaptoethanol, buffer); sample beam: (Nbf-Cl+2-mercaptoethanol,

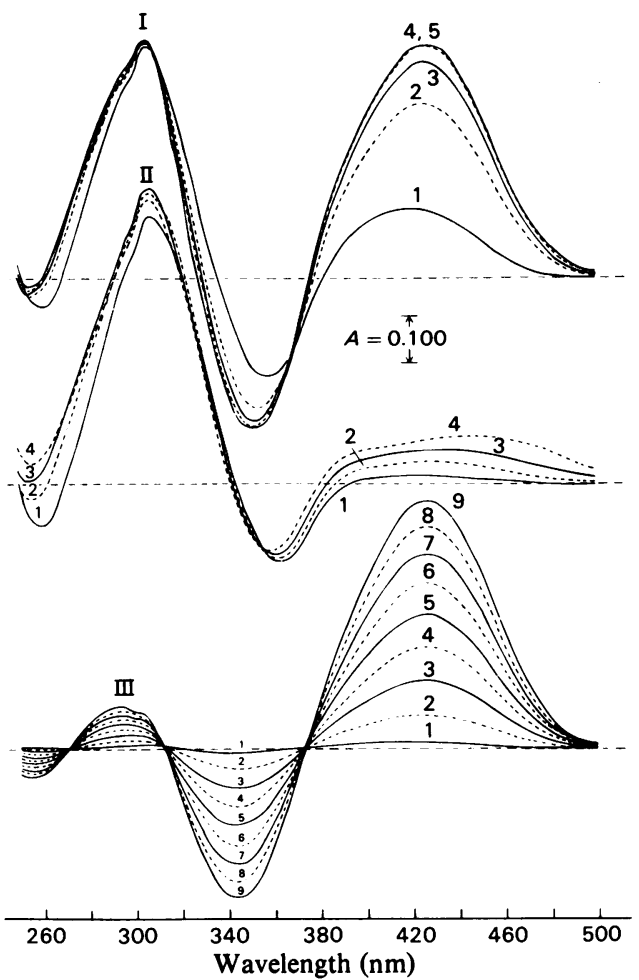

Fig. 4. Difference spectra of mixtures of $\mathrm{Nbf}-\mathrm{Cl}$ and 2mercaptoethanol at ambient temperature

The spectra were scanned at a rate of $30 \mathrm{~nm} / \mathrm{min}$ from high to low wavelength. The times given below are for the initial wavelength in the scan. The solution containing the $\mathrm{Nbf}-\mathrm{Cl}+2$-mercaptoethanol was in the sample beam (see the text for details). The spectra in set $\mathrm{I}$ were obtained in $0.05 \mathrm{M}$-triethanolamine $\mathrm{HCl} / \mathrm{NaOH}(\mathrm{pH} 7.5)$ at an $\mathrm{Nbf}-\mathrm{Cl}$ concentration of $0.102 \mathrm{~mm}$ and a 2 -mercaptoethanol concentration of $2.28 \mathrm{~mm}$. The times for the individual curves in set $I$ were $2 \mathrm{~min}$ (curve 1), $12 \mathrm{~min}$ (curve 2), $22 \mathrm{~min}$ (curve 3 ), $42 \mathrm{~min}$ (curve 4 ) and $72 \mathrm{~min}$ (curve 5). The spectra in set II were obtained in $0.05 \mathrm{M}$-triethanolamine $\mathrm{HCl} / \mathrm{NaOH}$ buffer ( $\mathrm{pH} 7.5)$ at an $\mathrm{Nbf}-\mathrm{Cl}$ concentration of $0.104 \mathrm{~mm}$ and a 2 -mercaptoethanol concentration of $22.8 \mathrm{~mm}$. The times for the individual curves in set II were $3 \mathrm{~min}$ (curve 1), $15 \mathrm{~min}$ (curve 2), $35 \mathrm{~min}$ (curve 3 ) and $60 \mathrm{~min}$ (curve 4 ). The spectra in set III were obtained in $0.05 \mathrm{M}$-sodium citrate/citric acid buffer (pH5.0) at an $\mathrm{Nbf}-\mathrm{Cl}$ concentration of $0.112 \mathrm{~mm}$ and a 2-mercaptoethanol concentration of $2.28 \mathrm{~mm}$. The times for the individual curves of set III were $3 \mathrm{~min}$ (curve 1), $27 \mathrm{~min}$ (curve 2), $57 \mathrm{~min}$ (curve 3), $87 \mathrm{~min}$ (curve 4), $117 \mathrm{~min}$ (curve 5), $147 \mathrm{~min}$ (curve 6), $177 \mathrm{~min}$ (curve 7), $207 \mathrm{~min}$ (curve 8) and $237 \mathrm{~min}$ (curve 9).

buffer); (buffer). The expected difference spectrum where $\mathrm{Nbf}-\mathrm{S}$ is the only product should exhibit a 
positive band at approx. $425 \mathrm{~nm}$, corresponding to product formation, and a negative band at approx. $343 \mathrm{~nm}$, corresponding to disappearance of $\mathrm{Nbf}-\mathrm{Cl}$ (see Fig. 3 for absolute spectra of $\mathrm{Nbf}-\mathrm{Cl}$ and of the Nbf-S derivative of 2-mercaptoethanol). Furthermore, the ratio $A_{425} / A_{343}$ should be independent of time. The difference spectra obtained at pH5.00 (curves III, 1-9, Fig. 4) appear to correspond solely to formation of the Nbf-S derivative of 2-mercaptoethanol. When the observed absorbances were plotted as a function of time and values of $A$ interpolated for corresponding times, the ratio $A_{425} / A_{343}$ was equal to $1.693 \pm 0.015$ for the entire time range examined, approx. $250 \mathrm{~min}$. The difference spectra at pH 7.50 (curves I, 1-5, and II, 1-4, Fig. 4) showed by contrast bands that could not be accounted for on the basis of formation of Nbf-S. With a 20-fold excess of 2-mercaptoethanol (curves I, Fig. 4), a positive band is observed at about $420 \mathrm{~nm}$ that shifts with increasing time toward longer wavelengths. It seems likely that this band corresponds, at least in part, to formation of the Nbf-S derivative of 2mercaptoethanol. The negative band at $358 \mathrm{~nm}$, which shifts toward $350 \mathrm{~nm}$ with increasing time, reflects, in part, disappearance of $\mathrm{Nbf}-\mathrm{Cl}$.

The most striking feature of these spectra is the positive band observed at $305-307 \mathrm{~nm}$. The amplitude of this band changes very little with increasing time, attaining its near-maximal value at the earliest time observed. This band must correspond to a product other than the Nbf-S adduct. The fact that this difference band attains its near-maximal amplitude at the earliest time observed suggests that this product is formed more rapidly than Nbf-S.

The product corresponding to the $307 \mathrm{~nm}$ band is formed with the release of protons. Addition of Nbf$\mathrm{Cl}$ to thiol compound (molar ratio, thiol compound/ $\mathrm{Nbf}-\mathrm{Cl}, 50: 1)$ in an unbuffered solution maintained at $\mathrm{pH} 7.00$ in a $\mathrm{pH}$-stat gave rise to a very rapid titration with base to compensate for proton release. Subsequent addition of base was much slower as protons were released during formation of $\mathrm{Nbf}-\mathrm{S}$.

The exact shape of the $307 \mathrm{~nm}$ band cannot be determined directly, since it is obscured by the spectral changes corresponding to disappearance of $\mathrm{Nbf}-\mathrm{Cl}$ and appearance of Nbf-S. The shifts of the $358 \mathrm{~nm}$ and the 425 to $430 \mathrm{~nm}$ bands relative to the peak positions for $\mathrm{Nbf}-\mathrm{Cl}$ and the $\mathrm{Nbf}-\mathrm{S}$ adduct of 2-mercaptoethanol (see Fig. 3), however, suggest that the $307 \mathrm{~nm}$ band in the difference spectrum may correspond in a component-resolved absolute spectrum to a band extending to much longer wavelengths or to formation of a second product (see below).

When the molar ratio of 2-mercaptoethanol to $\mathrm{Nbf}-\mathrm{Cl}$ was increased to 220: 1 (curves II, 1-4, Fig. 4), the band near $420 \mathrm{~nm}$ was almost completely suppressed, indicating that virtually no Nbf-S adduct is formed. This is in accord with the kinetic observation

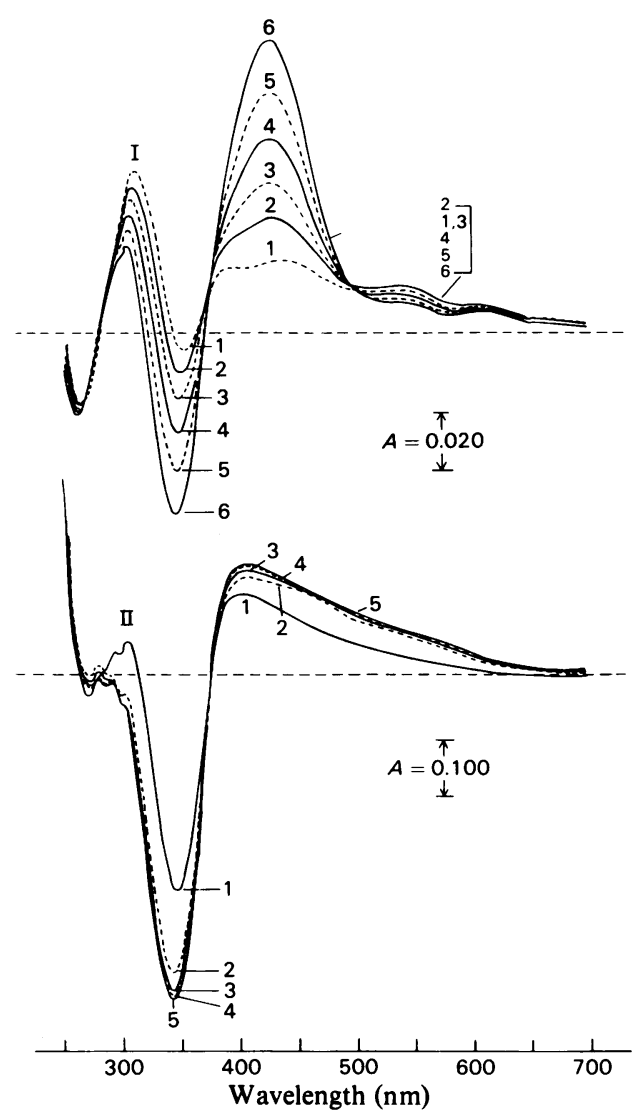

Fig. 5. Difference spectra of mixtures of $\mathrm{Nbf-Cl}$ and dithiothreitol at ambient temperature

Spectra were scanned at a rate of $30 \mathrm{~nm} / \mathrm{min}$ from high to low wavelength. The times given below were for the initial wavelength in the scan. The solution of $\mathrm{Nbf}-\mathrm{Cl}+$ thiol compound were in the sample beam (see the text for details). The buffer used was $0.05 \mathrm{M}$ triethanolamine $\mathrm{HCl} / \mathrm{NaOH}(\mathrm{pH} 7.5)$. The spectra of set I were obtained at an $\mathrm{Nbf}-\mathrm{Cl}$ concentration of $0.148 \mathrm{~mm}$ and a dithiothreitol concentration of $9.97 \times 10^{-3} \mathrm{~mm}$ at $3 \mathrm{~min}$ (curve 1), $13 \mathrm{~min}$ (curve 2), $23 \mathrm{~min}$ (curve 3), $38 \mathrm{~min}$ (curve 4 ), $58 \mathrm{~min}$ (curve 5) and $88 \mathrm{~min}$ (curve 6). The spectra in set II were obtained at an Nbf-Cl concentration of $0.0742 \mathrm{~mm}$ and a thiol concentration of $9.38 \mathrm{~mm}$ at $2 \mathrm{~min}$ (curve 1 ), $12 \mathrm{~min}$ (curve 2), $22 \mathrm{~min}$ (curve 3), $42 \mathrm{~min}$ (curve 4), and $72 \mathrm{~min}$ (curve 5).

(Fig. 2) that the rate constant for formation of Nbf-S decreased markedly with increase in 2-mercaptoethanol concentration when 2-mercaptoethanol was in excess. The negative difference spectral band near $360 \mathrm{~nm}$ and the large positive band observed at about $307 \mathrm{~nm}$ are comparable with those observed at the lower thiol compound concentration (cf. curves I and 
II, Fig. 4). The broadness of the positive band above $400 \mathrm{~nm}$ may be due to a 'tail' from the $307 \mathrm{~nm}$ band as suggested above. More likely, however, as will be seen with dithiothreitol $+\mathrm{Nbf}-\mathrm{Cl}$ difference spectra (see below), the broad band is due to product(s) other than that corresponding to the $307 \mathrm{~nm}$ band or to the Nbf-S adduct. It is especially interesting that the $307 \mathrm{~nm}$ peak begins to decrease in amplitude at the longest time observed, seemingly paralleling an increase in amplitude of the broad band above $400 \mathrm{~nm}$ (curves II, Fig. 4). The spectral changes that we observe, at least below $425 \mathrm{~nm}$, appear to correspond to those alluded to by other investigators, as summarized by Baines et al. (1977).

In looking at spectra of mixtures of dithiothreitol and $\mathrm{Nbf}-\mathrm{Cl}$ in buffer, it is apparent that the pattern of reaction of these substances resembles that observed with 2-mercaptoethanol (Fig. 4). In the presence of a large excess of $\mathrm{Nbf}-\mathrm{Cl}$ compared with dithiothreitol (curves I, 1-6, Fig. 5), a positive difference peak at about $310 \mathrm{~nm}$ is seen (compare with spectra for 2-mercaptoethanol, Fig. 4). The amount of this component disappears with time as an increasing amount of what appears to be the Nbf-S derivative is formed ( $425 \mathrm{~nm}$ band). A broad band extending out to $700 \mathrm{~nm}$ underlies the $\mathrm{Nbf}-\mathrm{S}$ peak. When dithiothreitol is in excess with respect to $\mathrm{Nbf}-\mathrm{Cl}$, the Nbf-S peak, if present at all, appears to be overwhelmed by the broad band extending from 400 to $700 \mathrm{~nm}$ (curves II, 1-5, Fig. 5), the band at approx. $307 \mathrm{~nm}$ being resolved only at the earliest time observed. (Such solutions have a purple-brown colour.) The amplitude of the very broad band is more than 10 times greater than that observed when $\mathrm{Nbf}-\mathrm{Cl}$ is in excess (cf. curves I and II, Fig. 5; note difference in scales for the two sets of curves). Thus the extent of formation of the coloured product is higher when dithiothreitol is in excess. Comparison of curves I and II of Fig. 5 likewise would suggest that as the thiol concentration is increased, coloured product is formed at the expense of $\mathrm{Nbf}-\mathrm{S}$ adduct.

It is noteworthy that indole and $\mathrm{Nbf}-\mathrm{Cl}$ at $\mathrm{pH} 5.00$ and 7.50, at concentrations of 458 and $134 \mu \mathrm{M}$ respectively, give rise to difference spectra (results not shown) with positive bands at about $300 \mathrm{~nm}$ and negative ones at approx. $360 \mathrm{~nm}$. These spectra developed more slowly than those seen with $\mathrm{Nbf}-\mathrm{Cl}$ and thiol compound and were clearly time-dependent. No such spectra were observed in solutions of $\mathrm{Nbf}-\mathrm{Cl}$ and anisole or imidazole. These observations with indole are of interest in terms of our conclusion that $\mathrm{Nbf}-\mathrm{Cl}$ and 2-mercaptoethanol form a reversible Meisenheimer-type complex (see the Discussion section).

\section{Effect of $\mathrm{Nbf-Cl/thiol} \mathrm{compound} \mathrm{reaction} \mathrm{products} \mathrm{on}$ proteins}

Although virtually complete reversal of inhibition of RNA polymerase activity by $\mathrm{Nbf}-\mathrm{Cl}$ can be achieved on addition of 2-mercaptoethanol or dithiothreitol when excess $\mathrm{Nbf}-\mathrm{Cl}$ is removed before addition of thiol compound (Bratcher \& Kronman, 1977), if thiol compound is added without such removal a purple-brown colour develops and irreversible inactivation occurs. The visible spectrum of the product shows a broad band extending from $700 \mathrm{~nm}$ down to the u.v. region. The spectral features closely resemble those observed with excess of thiol compound and Nbf-Cl (Figs. 4 and 5). Similar observations were made with bovine serum albumin that had been treated with $\mathrm{Nbf}-\mathrm{Cl}$ and then with dithiothreitol in a manner similar to that used with RNA polymerase. The characteristic visible spectral features were retained for both serum albumin and RNA polymerase even after the proteins were denatured and dialysed against $6 \mathrm{M}$-guanidine hydrochloride. These observations suggest that the coloured product is either very strongly bound to the protein or is covalently attached. The significance of these observations will be considered in the Discussion section.

\section{Discussion}

Our kinetic and spectroscopic observations indicate that $\mathrm{Nbf}-\mathrm{Cl}$ and low-molecular-weight thiol compounds form products above $\mathrm{pH} 5.00$ other than the Nbf-S compound. The product or products, which we designate $P_{2}$, appear to form in significant amounts when thiol compound is present in a large excess. We shall consider the properties of $\mathbf{P}_{2}$ subsequently.

The rate of formation of the second product, designated $P_{1}$, corresponding to the $307 \mathrm{~nm}$ band in the difference spectra (Figs. 4 and 5) appears to be faster than that of the Nbf-S product. The rapid release of protons in the $\mathrm{pH}$-stat experiments in mixtures of $\mathrm{Nbf}-\mathrm{Cl}$ and thiol compound and the small amplitude of the $307 \mathrm{~nm}$ band at pH5.00 (Fig. 4) suggest that the rate of formation of $\mathrm{P}_{1}$ is $\mathrm{pH}$ dependent. The detailed study of the reaction of $\mathrm{OH}^{-}$ with $\mathrm{Nbf}-\mathrm{Cl}$ by Baines et al. (1977) provides a useful framework in considering the formation of NbfOHEtS and $P_{1}$. Their observations strongly support the view that in addition to the C-4 alkylation product (III, Scheme 1) a reversible Meisenheimer complex (Meisenheimer, 1902) forms at C-6 (IV). If we identify $\mathbf{P}_{1}$ with this Meisenheimer complex with $\mathrm{RX}^{-}$equal to $\mathbf{R S}^{-}$, we can describe the reaction of 2-mercaptoethanol and $\mathrm{Nbf}-\mathrm{Cl}$ by Scheme 2.

The following expression for the time-dependence of the concentration of $\mathrm{Nbf}-\mathrm{SR}$ can be derived, assuming $\mathrm{Nbf}-\mathrm{Cl}$ to be in excess.

$$
\begin{gathered}
{[\mathrm{Nbf}-\mathrm{SR}]=} \\
{[\mathrm{R}-\mathrm{SH}]_{0}\left[1-\exp \left(\frac{k_{0} K_{\mathrm{I}}[\mathrm{Nbf}-\mathrm{Cl}]_{\mathrm{o}} /\left[\mathrm{H}^{+}\right]}{1+K_{0} K_{\mathrm{I}}[\mathrm{Nbf}-\mathrm{Cl}]_{0} /\left[\mathrm{H}^{+}\right]}\right) t\right]}
\end{gathered}
$$

Vol. 177 
<smiles>[R2]n1onc2c(=[N+]([O-])[O-])ccc(Cl)c1-2</smiles>

(V)<smiles>O=[N+]([O-])c1ccc(Cl)c2nonc12</smiles>

(I)<smiles>[R2]C1(Cl)C=CC(=[N+]([O-])[O-])c2nonc21</smiles>

(II)<smiles></smiles>

(III)<smiles>[R10]#C</smiles><smiles>[R2]C1([R4])C=C(Cl)c2nonc2C1=[N+]([O-])[O-]</smiles>

(IV)

Scheme 1. Reaction of $\mathrm{Nbf-Cl}$ with a nucleophile $R X^{-}$(taken from Baines et al., 1977)

$$
\begin{aligned}
& \mathrm{Cl}^{-}+\mathrm{NBf}-\mathrm{SR} \stackrel{k_{0}}{\longleftarrow} \mathrm{NBf}-\mathrm{Cl}+\mathrm{R}-\mathrm{S}^{-} \stackrel{K_{0}}{\stackrel{+}{\leftrightarrows}} \mathrm{P}_{1} \\
& \mathbf{H}^{+} \\
& K_{1} \uparrow \\
& \text { R-SH }
\end{aligned}
$$

Scheme 2. Reaction of $\mathrm{Nbf-Cl}$ with a thiol compound $R-S^{-}$ to form the covalent product $N b f-S R$ and the Meisenheimer complex $P_{1}$

The equilibrium constant, $K_{0}$, for formation of the $P_{1}$ complex is defined as an association constant.

where $[\mathrm{R}-\mathrm{SH}]_{0}$ and $[\mathrm{Nbf}-\mathrm{Cl}]_{0}$ are the initial concentrations of the reactants and $K_{1}$ is the ionization constant for 2-mercaptoethanol. The apparent first-order rate constant, $k_{\text {app. }}$, for formation of $\mathrm{Nbf-SR}$ will thus be:

$$
k_{\text {app } .}=\frac{k_{0} K_{\mathrm{I}}[\mathrm{Nbf}-\mathrm{Cl}]_{0} /\left[\mathrm{H}^{+}\right]}{1+K_{0} K_{\mathrm{I}}[\mathrm{Nbf}-\mathrm{Cl}]_{0} /\left[\mathrm{H}^{+}\right]}
$$

Fig. 6 shows a plot of the kinetic data obtained with 2-mercaptoethanol for the $\mathrm{pH}$ range $5-7.5, \mathrm{Nbf}-\mathrm{Cl}$ concentration, $0.2-2 \mathrm{~mm}$. The line was fitted to the data by the method of Kita et al. (1976). $\log \left(k_{\text {app. }}\right)$ approached a linear dependence on $\log \left([\mathrm{Nbf}-\mathrm{Cl}]_{0} /\right.$ $\left.\left[\mathrm{H}^{+}\right]\right)$at low values of this parameter, in accord with

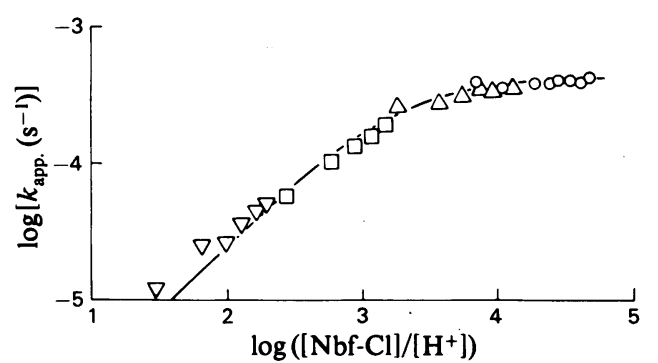

Fig. 6. Dependence of the apparent first-order rate constant on the parameter log $\left([\mathrm{Nbf}-\mathrm{Cl}] /\left[\mathrm{H}^{+}\right]\right)$for reaction of $\mathrm{Nbf}-\mathrm{Cl}$ with 2-mercaptoethanol at pH7.50 (O), $7.00(\triangle), 6.00(\square)$ and $5.00(\nabla)$

The data are identical with those of Fig. 1.

the predictions of eqn. (2). The linear portion of the curve had a slope of 0.91 in reasonable agreement with the stoicheiometry of Scheme 2. Eqn. (2) likewise predicts that with an increase in $[\mathrm{Nbf}-\mathrm{Cl}]_{0} /\left[\mathrm{H}^{+}\right]$, $k_{\text {app. }}$ should approach a limiting value, $k_{0} / K_{0}$. $\log \left(k_{\text {app. }}\right)$ does approach such a limiting value (Fig. 6). By using a value of $3.16 \times 10^{-10}$ for the ionization constant, $K_{1}$, of 2-mercaptoethanol (Tanford, 1962) and the data of Fig. 6, we obtain values of $2.8 \times 10^{-7}$ litre $\cdot \mathrm{mol}^{-1} \cdot \mathrm{s}^{-1}$ and $1.8 \times 10^{6}$ litre $\cdot \mathrm{mol}^{-1}$ for $k_{0}$ and $K_{0}$ respectively. The value of $1.8 \times 10^{6}$ obtained for $K_{0}$, the association constant for formation of the 
putative C-6 Meisenheimer complex of $\mathrm{Nbf}-\mathrm{Cl}$ and 2-mercaptoethanol, is about 250 -fold greater than the value obtained by Baines et al. (1977) for the $\mathrm{OH}^{-}$ complex.

The kinetics observed for formation of $\mathrm{Nbf}$ OHEtS are inconsistent with the direct formation of $\mathbf{P}_{2}$ from $\mathrm{Nbf}-\mathrm{Cl}$ and thiol compound (Scheme 3).

In this pathway, the apparent rate of formation of Nbf-SR should have a comparable dependence on $\mathrm{Nbf}-\mathrm{Cl}$ and on 2-mercaptoethanol concentration, irrespective of which is in excess. What we observe, however, is that the apparent first-order rate constant shows an increase with increase in $\mathrm{Nbf}-\mathrm{Cl}$ concentration when this reagent is in excess (Fig. 1) and a decrease with increase in 2-mercaptoethanol concentration when the thiol compound is in excess (Fig. 2).

Our observations do not allow us to specify a unique pathway for formation of $P_{2}$. The broad absorption spectrum extending to rather long wavelengths (Figs. 4 and 5) suggests that the product is of much greater complexity than $\mathrm{P}_{\mathbf{1}}$ or $\mathrm{Nbf}-\mathrm{SR}$.

Some remarks are in order on interpretation of kinetic observations with RNA polymerase in terms of the present study. Reaction of $\mathrm{Nbf}-\mathrm{Cl}$ with this enzyme has been shown to be radically different (Bratcher \& Kronman, 1977) from that observed with other thiol-group reagents. The reaction of RNA polymerase with $\mathrm{Nbf}-\mathrm{Cl}$ gives unique reaction at a single thiol group to specifically impair the elongation phase of RNA synthesis. No such unique thiol group has been observed with other thiol reagents. Baines et al. (1977) have suggested that $\mathrm{Nbf}-\mathrm{Cl}$ might form a Meisenheimer complex with a highly nucleophilic centre in a protein, bringing about a conformational change that would then give rise to direct alkylation at the usual C-4 position. The unusual reactivity of RNA polymerase with $\mathrm{Nbf}-\mathrm{Cl}$ appears to be an example of this type of process [detailed experimental spectroscopic and kinetic evidence has been obtained (M. J. Kronman, K. Nitta \& S. C. Bratcher, unpublished work)].

The complex reaction pattern of $\mathrm{Nbf}-\mathrm{Cl}$ with lowmolecular-weight thiol compounds would appear to complicate the use of this reagent in characterizing thiol-group reactivity in proteins. Although the protein concentrations employed are frequently much lower than those of the low-molecular-weight thiol

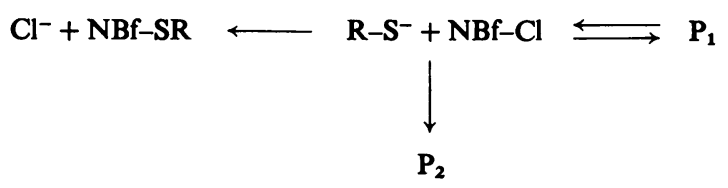

Scheme 3. Reaction of $\mathrm{Nbf}-\mathrm{Cl}$ with a thiol compound $\mathrm{R}-\mathrm{S}^{-}$ to form the coloured product $P_{2}$ as well as the Meisenheimer complex $P_{1}$ and covalent product $N b f-S R$ compounds used in the present study, it is apparent from our studies with $E$. coli RNA polymerase that reaction(s) similar to those observed in this study can influence the kinetics of formation of the Nbf-S product.

Great care must be employed in the use of this reagent in kinetic studies above $\mathrm{pH} 5$ to ensure that complex-formation does not obscure the rate of formation of the Nbf-S derivative. Determination of the dependence of rate constants on $\mathrm{Nbf}-\mathrm{Cl}$ concentration should provide an indication if such complexformation does occur.

Finally, we address ourselves to the question of the apparent reversibility of formation of the $\mathrm{Nbf}-\mathrm{S}$ derivative of proteins. We have shown that when high concentrations of thiol compound, such as 2-mercaptoethanol or dithiothreitol, are added to proteins in the presence of relatively high concentrations of $\mathrm{Nbf}-\mathrm{Cl}$, irreversible reactions occur with such proteins, giving rise to coloured products having broad spectral bands between 400 and $700 \mathrm{~nm}$. The consequence of this reaction for RNA polymerase was irreversible inactivation (Bratcher \& Kronman, 1977). This inactivation could be avoided by gel filtration of the $\mathrm{Nbf}-\mathrm{Cl} /$ enzyme reaction mixture to remove free reagent before addition of low-molecularweight thiol compound.

Since the nitrobenzofurazan derivative of an amino group cannot be thiolysed, it is particularly important to follow the above procedure when restoration of enzymic activity after addition of dithiothreitol or 2-mercaptoethanol is used as a means of distinguishing catalytically significant reaction at thiol and at amino groups. Application of this gel-filtration procedure, together with use of spectroscopic criteria (Birkett et al., 1970a) for the reaction at these two kinds of groups should provide unambiguous evidence for the identification of thiol as a group that can influence catalytic activity. This procedure was followed with RNA polymerase (Bratcher \& Kronman, 1977).

This research was supported by a grant from the National Institutes of Health (no. GM21187 and Institutional grant no. 580PR0540216). K. N. thanks the Yoshida Kagaku-Gijutsu Zaidan (Yoshida Science and Engineering Foundation) for a transportation fund. We thank Dr. Robert Stach for many helpful discussions of these observations.

\section{References}

Allen, G. \& Lowe, G. (1973) Biochem. J. 133, 679-686

Baines, B. S., Allen, G. \& Brocklehurst, K. (1977) Biochem. J. 163, 189-192

Birkett, D. J., Price, N. C., Radda, G. K. \& Salmon, A. G. (1970a) FEBS Lett. 6, 346-348

Vol. 177 
Birkett, D. J., Freedman, R. B., Price, N. C. \& Radda, G. K. $(1970 b)$ in Chemical Reactivity and Biological Role of Functional Groups in Enzymes (Smellie, R. M. S., ed.), pp. 147-155, Academic Press, London

Birkett, D. J., Dwek, R. W., Radda, G. K., Richards, R. E. \& Salmon, A. G. (1971) Eur. J. Biochem. 20, 494-508

Bratcher, S. C. \& Kronman, M. J. (1977) Biochem. Biophys. Res. Commun. 79, 203-209

Cantley, L. C., Jr. \& Hammes, G. G. (1976) Biochemistry 14, 2968-2975

Dwek, R. W., Radda, G. K., Richards, R. E. \& Salmon, A. G. (1972) Eur. J. Biochem. 29, 509-514

Ferguson, S. J., Lloyd, W. R. \& Radda, G. K. (1974) FEBS Lett. 38, 234-236
Ghosh, P. G. \& Whitehouse, M. W. (1968) Biochem. J. 108, 155-156

Herskovits, T. T. \& Laskowski, M., Jr. (1962) J. Biol. Chem. 237, 2481-2492

Kita, N., Kuwajima, K., Nitta, K. \& Sugai, S. (1976) Biochim. Biophys. Acta 427, 350-358

Meisenheimer, J. (1902) Justus Liebigs Ann. Chem. 323, 205-246

Nelson, W., Kanner, B. I. \& Gutnick, D. L. (1974) Proc. Natl. Acad. Sci. U.S.A. 71, 2720-2724

Price, N. C. (1972) Fed. Proc. Fed. Am. Soc. Exp. Biol. abstr. no. 1623

Shipton, M., Stuchbury, T. \& Brocklehurst, K. (1976) Biochem. J. 159, 235-244

Tanford, C. (1962) Adv. Protein Chem. 17, 70-161 